\title{
FILM SEBAGAI MEDIA SOCIAL MARKETING: YASMIN AHMAD BERJUALAN IDE MULTIKULTURALISME
}

\author{
Rosidah Syaukat; Ekky Imanjaya \\ Jurusan Marketing Communication, Fakultas Komunikasi dan Multimedia, BINUS University \\ Jl. K.H. Syahdan No. 9, Kemanggisan, Palmerah, Jakarta 11480 \\ danu@binus.edu
}

\begin{abstract}
Film is a message disseminating media and also mass communication tool. This statement sometimes appears when we are in film study. Film, and media in general, could be an effective propaganda. As a media, film could be used as a media to promote community awareness towards goodness issues. The question is how far we could consider film as one media to social marketing? The article discusses whether we could consider film as social marketing media. If it could be considered, what kind of films and how. Researcher took case study of Yasmin Ahmad's films, Malaysian's director, to analyze social marketing inside. All Yasmin's films that could be analyzed in this research consist of multiculturalism issue, covered by love story or family issues. Hopefully this article is becoming a beginning study so other researchers could analyze films and film-makers in Indonesia.
\end{abstract}

Keywords: film, Yasmin Ahmad, multicultural, social marketing

\begin{abstract}
ABSTRAK
Film merupakan media penyampai pesan dan alat komunikasi massa. Pernyataan ini acap terdengar bila kita masuk dalam kajian perfilman. Film, dan media pada umumnya, dapat menjadi alat propaganda yang ampuh. Dilihat sebagai suatu media, film dapat digunakan sebagai media untuk mempromosikan kesadaran masyarakat terhadap isu-isu kebaikan. Pertanyaannya: sejauh mana kita bisa mempertimbangkan film sebagai salah satu media untuk social marketing? Tulisan ini membahas apakah kita dapat mempertimbangkan film sebagai media social marketing. Jika dapat, maka jenis film yang bagaimana dan seperti apa. Peneliti mengambil studi kasus film-film Yasmin Ahmad, sutradara asal Malaysia, untuk menganalisis kandungan social marketing di dalamnya. Semua film Yasmin yang menjadi bahan analisis dalam tulisan ini dengan konsisten mengandung isu multikulturalisme, dengan dibalut dengan kisah cinta atau nilai-nilai kekeluargaan. Semoga artikel ini menjadi semacam studi awal sehingga peneliti lainnya dapat menganalisis sineas dan film-film Indonesia.
\end{abstract}

Kata kunci: film, Yasmin Ahmad, multicultural, social marketing 


\section{PENDAHULUAN}

Film merupakan media penyampai pesan dan alat komunikasi massa. Pernyataan ini acap terdengar bila kita masuk dalam kajian perfilman. Film, dan media pada umumnya, dapat menjadi alat propaganda yang ampuh. Bahkan UU Film Indonesia menyebut film sebagai “...karya seni budaya memiliki peran strategis dalam peningkatan ketahanan budaya bangsa dan kesejahteraan masyarakat lahir batin untuk memperkuat ketahanan nasional" dan "film sebagai media komunikasi massa merupakan sarana pencerdasan kehidupan bangsa, pengembangan potensi diri, pembinaan akhlak mulia, pemajuan kesejahteraan masyarakat, serta wahana promosi Indonesia di dunia internasional” (RI, 2009).

Film sebagai alat propaganda, dalam rangka mempengaruhi sikap dan perilaku sosial politik rakyatnya, sudah sejak 1898 (Film Reference.Com, n.d.a). Produksi film dinasionalisasikan paska Revolusi Bolshevik, tahun 1917. Menurut Vladimir Lenin (dalam Film Reference.Com, n.d.b), "Dari semua kesenian, bagi kami, sinema adalah yang paling penting.” Maka Rusia pun memproduksi filmfilm propaganda seperti Sergei Eisenstein dan, V. I. Pudovkin. Jerman di masa Nazi juga menggunakan film sebagai alat propaganda dengan Leni Riefenstahl sebagai salah satu sineas utamanya (Subterranean Cinema, n.d.).

Di Indonesia, film sebagai alat penyampai pesan sudah ada sejak masa kolonial Belanda. Kala itu, film dokumenter menjadi alat penyuluhan untuk pencegahan wabah penyakit pes dan transmigrasi (Tanah Sabrang, Mannus Franken, 1938) yang memakai punakawan, karakter dari dunia wayang (Imanjaya, 2010). Pada masa pendudukan Jepang, ia dimanfaatkan untuk meyakinkan bangsa Indonesia bahwa Jepang adalah saudara tua Asia yang akan membantu membebaskan Indonesia dari penjajahan Barat (Imanjaya, 2010).

Dalam dunia pemasaran atau marketing dikenal istilah yang kurang lebih sama fungsinya dengan penyebaran propaganda: pemasaran sosial (social marketing). Tujuannya adalah untuk mencapai tujuan perilaku tertentu untuk kebaikan sosial. Social marketing dapat diterapkan untuk mempromosikan hal-hal kebaikan, atau mencegah hal-hal yang buruk, misalnya mengajak masyarakat tidak merokok di ruang publik, penggunakan sabuk pengaman, penggunakan helm untuk kendaraan bermotor dan masih banyak lagi.

\section{Social Marketing}

Istilah social marketing lahir di tahun 1970an saat Kotler \& Zaltman (1971) menyadari bahwa prinsip-prinsip pemasaran yang dipakai untuk menjual produk ke konsumen bisa dipakai juga untuk menjual ide, sikap, dan perilaku. Kotler \& Andreasen (2002) menyatakan bahwa social marketing berupaya mempengaruhi perilaku sosial tidak untuk semata-mata keuntungan marketer, tapi juga kepada penonton yang ditargetkan dan juga masyarakat pada umumnya.

Menurut Kotler \& Roberto (1989), social marketing adalah teknologi manajemen perubahan sosial yang melibatkan desain, implementasi, dan pengendalian program-program yang bertujuan untuk meningkatkan penerimaan ide atau praktik sosial dalam satu atau lebih kelompok pengadopsi sasaran. Lebih lanjut mereka mengatakan social marketing menggunakan konsep-konsep dari segmentasi pasar, penelitian konsumen, pengembangan dan pengujian konsep produk, komunikasi terarah, fasilitasi, insentif, dan teori pertukaran untuk memaksimalkan respon dari target pengadopsi. Para pelaku yang mensponsori kegiatan ini berusaha untuk mengejar tujuan adanya perubahan dengan keyakinan bahwa mereka akan memberikan kontribusi terhadap kepentingan terbaik individu atau masyarakat. 
Menurut Lefebvre (2011), social marketing adalah aplikasi dari prinsip-prinsip dan teknik marketing untuk mendorong terjadinya perubahan atau perbaikan sosial, baik itu menyangkut masalah kesehatan publik, pencegahan kecelakaan, isu-isu lingkungan hidup, manajemen tuntutan transportasi atau kebutuhan-kebutuhan sosial yang lainnya.

Untuk menyebarkan ide ini, peran media sangat penting. Media komunikasi massa adalah “...terlibat dalam 'distribusi pesan' atau 'penyampaian pesan'...” sehingga media adalah “...saluran utama untuk memasarkan dan mendistribusikan produk sosial yang tak tampak (intangible)” (Kotler \& Roberto, 1989). Contoh media yang dimaksud, di antaranya, adalah televisi, radio, koran, majalah, komik, jurnal perdagangan, publikasi asing, iklan luar ruangan, iklan transit, poster, dan bioskop. Karena bioskop dianggap sebagai tempat distribusi yang signifikan, maka kita dapat menyimpulkan bahwa film menjadi media social marketing yang penting.

\section{Kampanye Perubahan Sosial}

Kampanye perubahan sosial bukanlah suatu hal yang baru. Sejak dari abad ke-17 hal tersebut sudah banyak dilakukan oleh beberapa negara di dunia. Pada masa sekarang, kampanye perubahan sosial banyak difokuskan pada: (1) kegiatan reformasi kesehatan, seperti anti rokok, peningkatan nutrisi, pencegahan penyalahgunaan narkoba; (2) reformasi lingkungan hidup, seperti kampanye air bersih, pencegahan polusi udara, pelestarian hutan; (3) reformasi pendidikan, seperti meningkatkan sarana sekolah negeri, peningkatan keahlian pada guru, peningkatan nilai siswa; dan (4) reformasi ekonomi, dengan menarik investor asing, peningkatan ketrampilan kerja dan pelatihan (Kotler \& Roberto, 1989).

Lalu apa yang dimaksudkan dengan kampanye perubahan sosial? Kotler \& Roberto (1989) pun menjelaskan bahwa kampanye perubahan sosial adalah suatu usaha yang dilakukan oleh satu kelompok (agen perubahan), yang bermaksud untuk membujuk orang lain (pengadopsi/kelompok sasaran) untuk menerima, memodifikasi, atau meninggalkan ide-ide, sikap, praktik, dan perilaku tertentu.

\section{Peran Sutradara sebagai Social Change Agent (Agen Perubahan)}

Dalam konteks kampanye perubahan sosial, agen perubahan sekaligus social marketer adalah pembuat film, yaitu produser dan/atau sutradara. Merekalah otak dari gagasan-gagasan yang tersimpan dalam media film dan kemudian disebarkan sebagai upaya untuk melakukan perubahan sosial. Karena itu, sangat penting untuk mengetahui langsung tujuan pembuatan film dari sang pembuat filmnya sendiri.

Selain itu, para agen perubahan ini perlu memiliki keahlian mengemas informasi (isu) yang ingin disampaikan sedemikian rupa sehingga dapat dimengerti dan diterima oleh kelompok pengadopsi sasaran. Hyman \& Sheatsley (dalam Kotler \& Roberto, 1989) menyimpulkan bahwa kampanye penyampaian informasi seringkali gagal dikarenakan hal-hal berikut: (1) ada kelompok yang benar-benar tidak mengetahui apapun (the chronic know-nothings) yang memang mungkin tidak dapat dicapai oleh suatu kampanye; (2) kemungkinan seseorang menanggapi informasi baru (isu baru) meningkat seiring dengan minat atau keterlibatan mereka terhadap informasi tersebut. Jika hanya sedikit saja orang-orang yang berminat atau merasa memiliki kepentingan, maka sedikit pula yang akan menanggapi; (3) kemungkinan seseorang untuk menerima informasi baru meningkat seiring dengan kesesuaian informasi baru (isu baru) tersebut dengan sikap mereka sebelumnya. Orang akan cenderung menghindari informasi yang tidak menyenangkan tentunya; (4) kecenderungan masyarakat merespon dengan cara yang berbeda-beda terhadap informasi (isu) yang sama, tergantung dari keyakinan dan nilai yang dimiliki masing-masing. 
Film, dalam konteks ini pula, dianalogikan sebagai social product, sesuatu yang didesain oleh social marketer, sang agen perubahan. Kala mendesain sebuah kampanye, ada faktor-faktor penting dalam penggunaan media massa untuk mengubah perilaku dan sikap publik: faktor audiens, pesan, media, dan response-mechanism (Kotler \& Roberto, 1989). Tulisan ini berfokus pada penonton (sutradara harus menjadikan publik luas sebagai sasaran kampanyenya), pesan (nilai-nilai kebaikan, dalam hal ini multikulturalisme), dan media (film sebagai alat bertutur). Untuk faktor terakhir ini, Kottler \& Roberto (1989) menggarisbawahi bahwa social marketing adalah upaya mengombinasikan elemen-elemen terbaik dari pendekatan tradisional untuk perubahan sosial, dengan rencana dan kerangka kerja aksi yang terintegrasi, serta menggunakan teknologi komunikasi dan kemampuan pemasaran. Teknologi komunikasi dalam konteks tulisan ini adalah film, yaitu film-film karya Yasmin Ahmad.

Sedangkan pesan dalam istilah social marketing adalah social product yang terdiri dari ide, seperti keyakinan (belief), sikap (attitude) dan nilai-nilai (value), terapan sosial (aksi dan tindakan); serta objek yang tampak (tangible) misalnya, dalam konteks keluarga berencana, pil KB dan kondom (Kotler \& Roberto, 1989).

\section{Film sebagai Media Social Marketing}

Dilihat sebagai suatu media, film dapat digunakan sebagai media untuk mempromosikan kesadaran masyarakat terhadap isu-isu kebaikan seperti disebutkan di atas. Pertanyaannya: sejauh mana kita bisa mempertimbangkan film sebagai salah satu media untuk social marketing?

Tulisan ini membahas apakah kita dapat mempertimbangkan film sebagai media social marketing. Jika dapat, maka jenis film yang bagaimana dan seperti apa. Peneliti mengambil studi kasus film-film Yasmin Ahmad untuk menganalisis kandungan social marketing di dalamnya. Alasan-alasan Yasmin Ahmad yang diambil yaitu karena: sutradara sebagai social marketer, isi dan cara bertutur, konsistensi, serta target penonton yang luas.

Sang sutradara harusnya menjadi otak di balik gagasan social marketing ini. Artinya, sang sineaslah yang sedari awal memanfaatkan filmnya sebagai kampanye nilai-nilai kebaikan dan berniat menjadikan film sebagai media untuk mempengaruhi dan mengubah sikap dan perilaku penontonnya. Nilai kebaikan yang dimaksudkan adalah multikulturalisme. Karena itu, akan diperiksa lewat wawancara dan pemberitaan di media massa bahwa sang filmmaker memang bertujuan mempromosikan multikulturalisme. Artikel ini akan membuktikan bahwa Yasmin Ahmad, dengan pernyataan langsung darinya atau pun dari analisa jurnalistik dan akademis, memang bertujuan untuk mengangkat isu multikulturalisme dalam filmnya.

Yasmin memandang sinema sebagai sesuatu yang lebih besar dari sekadar hiburan. Ia selalu menyelipkan pesan multikulturalisme dalam hampir semua filmnya (Sepet, Gubra, Mukhsin, Talentime) juga iklan-iklan Petronas yang digarapnya dalam rangka Hari Kemerdekaan Malaysia, khususnya Percintaan Tan Ho Ming. Bagian ini juga akan dibuktikan di subbab analisa.

Semua film Yasmin yang menjadi bahan analisis dalam tulisan ini dengan konsisten mengandung isu multikulturalisme, dengan dibalut dengan kisah cinta atau nilai-nilai kekeluargaan. Selain itu, Yasmin Ahmad, sebagai social marketer, menargetkan filmnya kepada penonton yang lebih luas, tidak hanya untuk kalangan tertentu saja. Film-film Yasmin Ahmad memang langganan festival film internasional seperti Berlinale, tetapi juga sekaligus berada dalam urutan teratas dalam box office, yaitu yang paling ditonton oleh masyarakat awam. Poin ini juga akan dibuktikan dalam subbab di bawah nanti. Poin-poin di atas adalah elemen yang memperkuat alasan mengapa film-film Yasmin peneliti anggap sebagai implementasi social marketing. 


\section{PEMBAHASAN}

\section{Sang Sutradara sebagai social marketer}

Isu multikulturalisme selalu ada dalam mayoritas karya Yasmin. Beliau menganggap pembauran adalah isu besar di Malaysia, khususnya karena perempuannya Melayu. Dalam wawancara pribadi dengan Imanjaya ${ }^{1}$, beliau mengatakan: "Jadi masalah karena perempuannya Melayu. Kalau ceritanya tentang pria Malaysia dengan gadis China atau India, tidak akan jadi masalah. Tapi kalau sebaliknya, takkan bisa diterima masyarakat. Karena bagi pria Malaysia, mereka bisa menikah dengan ras apa pun, tapi tidak bagi perempuan Melayu. Jadinya, (untuk pria) tidak terlalu ofensif.”

Isu multiras ini selalu hadir di filmnya karena pengalamannya di masa lalu. Menurut Yasmin, "Saat saya kecil, ibu saya punya sahabat baik bernama Ibu Tan, seorang Cina. Saya rasa, itu sangat mempengaruhi sepanjang hidup saya. Lebih lanjut ia menjabarkan: "Jika Anda percaya dengan kemanusiaan, Anda akan peduli kepada semua orang. Orang tua sayalah, khususnya ibu saya yang punya sahabat dari semua ras, yang mempengaruhi saya untuk melihat masyarakat tanpa warna. Beliau selalu mengatakan pada saya bahwa manusia adalah manusia dan ketika kamu melihat orang yang berbeda denganmu, janganlah dibungkam dan jangan dicurigai hal-hal terburuk dari mereka" (Bissme, 2009). Isu pembauran dan agama yang disentuhnya adalah isu sensitif di Malaysia dan ada juga kelompok yang menganggapnya kontroversial. Tapi, Yasmin tetap membuat film bertema sejenis. Ia menegaskan bahwa tujuannya mengungkap isu sensitif adalah untuk membuat masyarakat bisa membicarakannya dengan perilaku yang beradab.

\section{Isi}

Film pertamanya yang dengan gamblang memasukkan pesan ini adalah Sepet (2004) alias Sipit. Ini adalah kisah romansa antara Orked (gadis muda Melayu Muslim) dengan Jason (pria muda, Cina, Katolik). Dari sini sudah terlihat potensi konflik yang kemungkinan terjadi. Seorang gadis Melayu makan di restoran Cina atau fasih menyanyikan lagu mandarin adalah hal yang tak lazim.

Berikutnya adalah Gubra (Cemas, 2006), yang masih bercerita tentang keluarga Orked, namun kali ini lebih dalam dan luas. Orked yang ketika di Sepet ditinggal wafat Jason, kini telah menjadi wanita matang dan menikahi seorang Cina-Muslim, Arif. Saat mengantarkan bapaknya yang terkena serangan jantung ke rumah sakit, ia sekali lagi bertemu dengan keluarga Jason-- berawal dari Alan sang adik, yang juga sedang dirundung duka di sana. Dan ada fakta mengejutkan: Ia mendapati suaminya bermain serong. Film ini mengandung pesan untuk memaafkan, seberat apapun itu, tapi tema multikulturalisme muncul lagi. Misalnya, Orked bertemu dengan Alan dan berdiskusi bahwa musik tidak lagi asyik kalau liriknya hanya satu bahasa." Saya akan keluar dari negeri ini kalau ini terjadi," ujar Orked.

Film terakhir dari trilogi Orked adalah Mukhsin (2006) yang berfokus pada cinta pertama Orked kala masih di bangku sekolah dasar. Film ini mendapat keuntungan RM 2 juta. Di sini digambarkan Orked yang Muslim bersekolah di sekolah Cina. Dan Mukhsin pun bertanya:

“Orked, mengapa ayahmu memasukkanmu ke sekolah Cina?”

"Mungkin Abah mau saya pandai bahasa Cina"

"Mengapa?"

"Karena Orked sudah pandai bahasa Melayu”

\footnotetext{
${ }^{1}$ Imanjaya, E. (2007). Wawancara pribadi dengan Yasmin Ahmad. Diakses pada 8 Maret 2011, dari http://old.rumahfilm.org/wawancara/wawancara_yasmin.htm
} 
Di Muallaf (diproduksi 2007 dan dirilis 2009), ada satu ras tambahan selain Melayu dan Cina, yaitu India. inilah cerita Ana dan Ani yang sedang dalam proses pencarian ketuhanan. Keduanya belajar agama, secara mandiri, mulai dari sosiologi agama hingga perbandingan agama. Mereka kabur dari ayahnya yang suka main tangan. Ani, sang adik, bersekolah di sekolah Katolik, dengan kepala sekolah seorang India dan juga ada guru muda Cina-Katolik, Brian, yang diam-diam mencintai Ana, sang kakak.

Terakhir, Talentime (2009), ada yang menjulukinya Malaysia High School Musical. "Ini film saya yang beautifully colorful", tulisnya di email yang ditujukan buat peneliti. Diceritakan, sekolah mengadakan kontes mencari bakat, 7 finalis akan tampil di acara ulang tahun sekolah itu. Melur, seorang Melayu Muslim, adalah salah satu pemenang. Sedangkan Mahesh adalah seorang India Hindu bisu yang ditugaskan mengantar-jemput Menur, bisa ditebak, keduanya saling jatuh cinta, dan mendapatkan perlawanan khususnya dari pihak Mahesh dengan alasan beda agama.

Film-film di atas tidak hanya berbahasa Melayu dan Inggris, yang menjadi bahasa utama di Malaysia, tetapi juga Cina, dan bahkan di Talentime ditambah dengan bahasa Hindi dan bahasa isyarat. Ini adalah fenomena yang jarang terjadi di sinema Malaysia (Muhammad, 2009).

Iklan yang dibuat Yasmin juga tak luput dari semangatnya menyebarkan ide multikulturalisme. Di antaranya, Tan Ho Ming untuk Petronas, dan Funeral untuk Kementrian Pemuda Singapura. Tan Ho Ming, seorang bocah cina, sekitar kelas 1 SD, diwawancara tentang sahabat sejati dan cinta pertama. Maka dia pun bercerita tentang wanita pujaannya. Tapi dia sangat malu untuk menyatakan cintanya. Dia hanya mencintai wanita itu diam-diam, begitu pengakuannya. Scene berikutnya, two shot, sang bocah Cina dan sahabatnya itu, seorang wanita Melayu berusia sebaya dengannya. Giliran sang gadis diwawancara. Dan dia menjawab: "pacar saya adalah dia", sambil menunjuk ke arah Tan Ho Ming. Begitu jawaban terdengar, si pria cilik langsung terkejut, matanya terbelalak, tangan kirinya menutup mulutnya, dan tangan kanannya mengandeng pasangannya menjauh dari kamera, dalam diam. Namun tetap dalam mulut yang ternganga tak percaya. Berikutnya, fade out, dan muncul kalimat: "Anak kecil itu buta warna. Mengapa kita harus mengubahnya?”

Funeral mempunyai pesan nilai-nilai keluarga. Seorang ibu dari ras India menyampaikan pidato di upacara kematian suaminya yang Cina. Disana, menjabarkan bahwa justru ketidaksempurnaan pasangan menjadikannya sempurna.

Cukup banyak tulisan, baik yang ilmiah atau popular, yang menganalisa film-film Yasmin Ahmad sebagai penganjur keharmonian dan multikulturalisme, meskipun kontroversial tak terhindarkan. Misalnya Ami (2009) dalam tulisan Controversies Surrounding Malaysian Independent Female Director Yasmin Ahmad's First Film, Sepet, menyatakan bahwa film Yasmin “...selalu menjelajahi kekayaan yang dimungkinkan dalam perjumpaan multiras”. Akademisi dari Australian National University, Gaik Cheng Kho, menulis The Politics of Love: Malaysia's Yasmin Ahmad (Khoo, 2007) dan Reading the films of independent filmmaker Yasmin Ahmad: cosmopolitanism, Sufi Islam and Malay subjectivity yang dimuat dalam buku Race and Multiculturalism in Malaysia and Singapore. Sedangkan Gerald Sim, dalam jurnal Film Quarterly, membuat tulisan berjudul Yasmin Ahmad's "Orked" Trilogy: Discusses Sepet (2004), Gubra (2006), and Mukhsin (2006), a Sequence of Films about an Adolescent Muslim Girl Falling in Love in Multicultural Malaysia.

Dari sisi jurnalistik, Bergan menulis obituari tentang Yasmin Ahmad di Guardian edisi 12 Agustus 2009. Bergan menulis bahwa karya Yasmin “...merefleksikan keragaman budaya dan etnis yang luas dari negerinya, serta kehidupan dan mimpi orang mudanya”. Lebih jauh, Bergan menyatakan: "Film-film Yasmin menantang stereotipe etnis, dan dia dengan terbuka melawan segala tipe fundamentalisme dan rasisme, dan membuat karyanya selalu mendukung hak-hak minoritas.” 
Tentang film terakhir Yasmin, Talentime (2009), Bergan menulis bahwa Yasmin "mengulang lagi tema tentang iman, toleransi, keluarga, dan hidup di masyarakat yang multikultural." Sedangkan, Muhammad (2009) menyatakan bahwa Yasmin berhasil melihat warisan multikultural sebagai sebuah rahmat daripada sebuah beban berat.

\section{Konsistensi}

Kalau kita lihat, semua karyanya mengandung ajakan untuk keharmonian dan kedamaian antar etnis dan ras, dalam konteks Malaysia: Melayu, Cina, dan India, dan mengatasi perbedaan. Menurut Yasmin, "Saya tidak tersinggung waktu diberitahu ada yang bilang bahwa saya punya tren tertentu di film-film saya. Semua sutradara yang saya kagumi punya tema-tema konsisten dalam film mereka. Banyak orang bertanya, mengapa saya tidak bikin film perang ada sci-fi dan membuktikan diri bahwa saya adalah pembuat film yang serba bisa. Saya tak pernah bikin film untuk dianggap sutradara serba bisa. Saya ingin memeriksa emosi-emosi. jika Anda ingin orang yang serba bisa, pergilah cari orang lain” (Bissme, 2009).

\section{Target Penonton}

Dalam wawancara peneliti dengan Yasmin (Imanjaya, 2007) menjelaskan bahwa ia membuat film untuk seluas mungkin penonton. Tujuannya membuat film ada tiga: “...karena ingin lebih memahami Tuhan dan diri sendiri lebih baik lagi, serta untuk membahagiakan orang tua dan temanteman dekat, bukan ingin lebih memahami juri-juri di festival.” Ia juga tidak mengotak-kotakkan filmnya sebagai film seni atau film komersial. "Saya tak mau menjadi art-house filmmaker. Saya tak mau. Saya mau film-film saya ditonton banyak orang” (Imanjaya. 2007). Lebih lanjut lagi, Yasmin menegaskan: "Saya percaya pada Shintaro Tanikawa dan Pablo Neruda. Neruda bilang, "I want my poetry to be like bread, everybody can eat it". Shintaro bilang, "aku tak mau pembaca saya menganalisa puisi saya. Saya mau puisi saya seperti makanan, dan saya harap mereka mencicipinya dan merasakan kenikmatannya”. Kedua tokoh itu adalah penyair terbesar yang pernah hidup menurut saya. Dan saya mengkiblatkan pada keduanya, karena mereka lebih hebat dari pembuat film seni yang membosankan” (Imanjaya, 2007).

\section{PENUTUP}

Media menjadi satu hal yang sangat penting untuk kampanye social marketing (Dagron \& Tufte, 2006). Dari berbagai media yang dapat digunakan, film merupakan salah satu media ampuh untuk social marketing; untuk mempromosikan ide-ide kebaikan kepada masyarakat dan mengajak mereka untuk mengubah sikap, perilaku atau praktik-praktik tertentu kearah yang lebih baik. Namun banyak hal yang harus diperhatikan atau dipenuhi agar efektivitas komunikasi melalui film dapat tercapai. Pesan atau social issue harus didesain sedemikian rupa agar dapat menarik perhatian pengadopsi atau kelompok sasaran. Dan juga dengan isi yang dapat dimengerti oleh khalayak ramai. Pemilihan isu, selain merupakan idealisme sang agen perubahan, seharusnya juga menyangkut kepentingan dan minat orang banyak. Dengan demikian kemungkinan masyarakat mau merespon dan menerima isu tersebut menjadi lebih tinggi. Sutradara dan/atau produser yang dalam hal ini berperan sebagai social marketer, haruslah memiliki pengetahuan yang baik dan tingkat sensitifitas yang tinggi dalam mengemas social product yang ingin disampaikan kepada publik. Mereka harus berperan sebagai agen perubahan yang melakukan kampanye-kampanye dalam rangka menawarkan nilai-nilai kepada penontonnya. Para agen perubahan tersebut juga harus secara jeli membidik (targeting) kelompok pengadopsi sasaran, agar pesan dapat secara efektif disampaikan kepada mereka. 
Berawal dari gagasan sang social marketer yang sekaligus sang sutradara, Yasmin Ahmad menyebarkan nilai-nilai keharmonisan dan kedamaian dalam masyarakat multikultur di dalam filmfilmnya. Yasmin pun dengan konsisten selalu menggarisbawahi isu multikultur dalam film-filmnya. Dan ia ingin agar pesannya dapat terdistribusi ke seluas mungkin jangkauan. Artinya, Yasmin membuat film arus utama bergenre drama dengan target pasarnya adalah masyarakat umum. Social marketer yang baik adalah agen perubahan yang dengan terang-terangan menyatakan kampanye untuk mengubah sikap dan perilaku masyarakat dengan menyebarkan ide-ide ke seluas mungkin konsumen. Artinya: ia memang memosisikan diri sebagai agen perubahan; ia membuat pesan berisi nilai-nilai kebaikan; ia mengemasnya dalam film yang dipahami dan bisa dinikmati sebanyak mungkin penonton; dan konsistensi adalah nilai plus. Yasmin Ahmad telah berhasil memenuhi keempat faktor di atas. Ia berusaha menciptakan suatu social product yang dapat diterima oleh semua kalangan. Berusaha agar kelompok-kelompok masyarakat yang semula tidak menyadari isu-isu multikulturalisme, menjadi tahu atau bahkan memahami isu tersebut, berkat konsistensinya dalam menanamkan ide tersebut dalam semua film-filmnya.

Banyak sekali film yang sarat dengan pesan idealis di Indonesia, tapi tidak memenuhi semua elemen di atas. Kendala terbesar adalah distribusi dan target penonton. Ada yang film yang pesannya bagus tapi tidak banyak yang menonton, atau hanya beredar dari festival ke festival dengan audiens yang sangat terbatas, atau sulit sekali publik dapat mengaksesnya. Sedangkan social marketer yang baik haruslah dapat mendesain social product-nya sedemikian rupa sehingga menjangkau pemirsa seluas-luasnya. Dari sekian banyak sutradara dan/atau produser Indonesia, yang paling mendekati keempat elemen di atas adalah Nia Dinata (ide kesetaraan gender dan feminisme serta hak minoritas gay-lesbian-biseksual-transeksual) dan Deddy Mizwar (kritik sosial, anti korupsi, clean government, dan demokrasi). Semoga artikel ini menjadi semacam studi awal sehingga peneliti lainnya dapat menganalisis sineas dan film-film Indonesia.

\section{DAFTAR PUSTAKA}

Ami, F. A. M. (2008). Controversies surrounding Malaysian independent female director Yasmin Ahmad's first film Sepet. Proceeding 17th Biennial Conference of the ASAA, Melbourne, Australia. Diunduh pada 8 Maret 2011, dari http://arts.monash.edu.au/mai/asaa/farahazaleamohamedalamin.pdf

Bergan, R. (2009). Obituary: Yasmin Ahmad. Guardian. Diakses pada 12 Agustus 2009, dari http://www.guardian.co.uk/global/2009/aug/12/obituary-yasmin-ahmad

Bissme, S. (2009). Yasmin's immortal words. Sun2Surf. Diakses pada 8 Maret 2011, dari http://www.sun2surf.com/article.cfm?id=36262

Dagron, A. G., \& Tufte, T. (Ed.). (2006). Communication for social change - Anthology: Historical and contemporary readings. New Jersey: Communication for Social Change Consortium.

Film Reference.Com. (n.d.a). Early film history and propaganda. Diakses dari http://www.filmreference.com/encyclopedia/Independent-Film-Road-Movies/PropagandaEARLY-FILM-HISTORY-AND-PROPAGANDA.html

Film Reference.Com (n.d.b.). Propaganda and nation. Diakses dari http://www.filmreference.com/encyclopedia/Independent-Film-Road-Movies/PropagandaPROPAGANDA-AND-NATION.html

Imanjaya, E. (2010). The Backdoors of Jakarta: Jakarta and social issues in post-reform Indonesian cinema. Saarbruecken: Lambert Academic Publishing. 
Khoo, G. Ch. (2007). The Politics of love: Malaysia's Yasmin Ahmad. Metro. Summer Issue 155 , 52-57.

Kotler, P., \& Andreasen, A. (2002). Strategic marketing for nonprofit organizations (6th ed.). Prentice Hall.

Kotler, P. \& Zaltman, G. (1971). Social marketing: an approach to planned social change. Journal of Marketing 35, 3-12.

Kotler, P., \& Roberto, E. L. (1989). Social marketing: Strategies for changing public behavior. New York: The Free Press Macmillan.

Lefebvre, C. (2011). An integrative model for social marketing. Journal of Social Marketing, $\quad$ Vol. 1 , Issue 1.

Muhammad, A. (2009). Yasmin Ahmad films. Kuala Lumpur: Matahari Books.

Republik Indonesia (2009). Undang-Undang Republik Indonesia Nomor 33 Tahun 2009 Tentang Perfilman, Lembaran Negara Republik Indonesia Tahun 2009 Nomor 141, Jakarta: Sekretariat Negara.

Subterranean Cinema. (n.d.). Nazi Cinema. Diakses dari http://www.subcin.com/nazi.html 